\title{
Impact of Banking Sector wise differences on High-Performance Work Practices
}

\author{
Preeti Vats ${ }^{1}$, Shivani Agarwal ${ }^{2}$ \\ ${ }^{I}$ Research scholar, Dr. APJ Abdul Kalam Technical University, \\ Assistant Professor (Kamal Institute of Higher Education and advance technology) \\ ${ }^{2}$ Corresponding Author, Assistant Professor, KIET School of Management, \\ KIET Group of Institutions, Delhi-NCR, Ghaziabad, India \\ Ipreetivats2515@gmail.com, ${ }^{2}$ jindal.shivani24@gmail.com
}

\begin{abstract}
The objective of this research paper is to comprehend the aspects of High-Performance Work-Practices pertinent to Government Undertaking public sector banks vis-à-vis their counterpart of private sector banks. The sample consists of 800 people, out of which 400 were public sector bank and 400 were from private sector banks. High-Performance Work Practices was measured through a four-dimensioned scale developed by Delery and Doty (1996). Significant differences regarding High-Performance Work Practices after data collection were tested using t-test. The findings reported noteworthy variance in the demonstration of many of the influencing factors of High-Performance Work Practices between the studied groups. The insights gained through this paper can be utilized to improve the level of High-Performance Outcome WorkPractices among the Government owned-public sector bank and privately owned-private sector banks. This study represents the data and delivers insights of the dimensions of HighPerformance Outcome Work-Practices of the workforce.
\end{abstract}

Keywords-High-Performance Outcome Work-Practices, Sector-wise differences, Public sector bank and Private sector banks

\section{INTRODUCTION}

A LL KIND of Banks are motivated to nurture and maximize their performance matrix in twenty-first century. Every Bank with different financial holding pattern, private or publicly funded of diverse size, sector and geography works onto increasing their quantitative and qualitative part of Banking performance matrices. Banks are focusing more on workforce parameter to improve their performance in all ways of their business operations as it is more leveraged on services sector. Banks are progressively directed on providing and assessing Workforce commitment, fulfilment and confidence to shoot any Bank to next level of Banking performance but also consider such features as Banks end result. Lot many manhours have gone into HPWPs since classical theorists to augment efficiency of workforce iteratively, which hypothesized scientific means of bank administration, banking values of administration and exercise of controls. Even today the emphasis is floated towards neohuman relation and neo-behaviorists thoughts. One of classical theorist Taylor and Fayol paved the way for supplementary structural feature of a Banking organization. They were of belief system that a methodically consequential and premeditated effort matrix encompassing the standard principles of administration will meaningfully add to upsurge the productivity of workforce having favourable impact on workforce confidence and fulfilment, which results in influencing the productivity and hence self-sufficient administration exercise would result into a high-level outcome performing enterprise. Weber established same and preferred balanced and lawful authority to increase an organizations performance. He expounded that fixed pre-known set of rules and protocols, meritocracy, accountability, tenure, unbiasedness and impartiality will lead an organization of future to its performance maximization route.

\section{CONCEPTUALIZING THE VARIABLES}

Numerous researches are conducted for High-Performance Outcome Work-Practices system, their inference, their comparative standing to Banks, but the current paper is for the baselining that silhouettes High-Performance Work Outcome system is considered on four constraints explicitly work-specification, Training, work-participation and worksecurity. A grading scale postulated by Doty and Delery (1996) is positioned to rate the workforce involvement of HPWPs in this paper. All the four scopes of dimension that were projected by Delery and Doty are represented underneath. All these extents are labelled in element to provide a better knowhow of HPWPs. The dimensions are as under:

2.1Training: Training is used as tool great usability tool for organizations that empowers a worker associate to a level where they can finish the assigned job to them - properly, thoroughly and effectively. Training is medium by which a staff's information and skillfulness for completing a particular work item. This denotes as a tool which can be used in all kind of Banks to bridge the know how gaps among standard protocols and actual performance appraise basis. In this paper numerous parameters are explicit to factor training in gauging or measuring the workforce experiment of HPWPs. This includes factors like how often training programs are rendered to workforces so that workforces can best utilized them. Widespread training program tools are undertaken to enhance the skills and know-how of the workforce when focus come into play in the Banks. This also signifies the reputation of training conferences delivered to the workers to augment their promotability in the Banks.

2.2Job participation: This parameter is demarcated with envisioning that a workforce engrossment offers workers a 
chance to get inspired and wherever fitting, permits them to aggressively be involved as a decision maker in the organization operational processes which impact their immediate work. This alters the mutual cognizance amid staffs and the organization administration. In this current paper numerous variables are considered and taken into interpretation to safeguard work participation of workforces comparable if the occasions are informed to the workforces to endorse the improvements in regard to ways of working as is currently completed. It regulates the degree of contribution of a workforce in organization verdicts taken by controller manager. It encompasses the amount of free communiqué between immediate supervisor and worker subordinates with respect to the professional apprehensions.

2.3Job Specification: A determination of staff physiognomies and schooling prerequisite compulsory for suitable recital of certain responsibilities and work item tasks encircling a explicit job function or work item function. Job specification is subsequent from the work scrutiny. Job specification assumes the personal, physical, mental and behavioral social topographies of the job staff. Job Specification sets the yardsticks of the know-how, capabilities and craftmanship that are essential to do a certain job efficiently. It regularly comprises structures like schooling, emotional behavior, training, corporeal skillset, communiqué skills, physical exertion undertaking and decision making etc.

2.4Job security: The work security is a necessity or reliance that a staff will endure to deliver the job work without endangering of becoming unemployable or un-employed. In deprivation of such job work security at work place signifies to a state in which a staff with a regular work item sees a greater probability of becoming unemployed in coming future. Job security typically be contingent on predominant baking business scene, economic situation and the individual working capacity. Job security usually follow from the details of the engagement contract, labor legislations or shared arrangement that prevents arbitrary dismissal of services of a workforce or workforce redundancies.

\section{LITERATURE REVIEW}

Applebaum et al. (2000) pondered plentiful multinationals connected to the manufacturing of steel melting, apparels, medical devices and apparatus's. From worker assessments, seminars with administrators and union legislatures and steel plant site co-visits, they founded that high-performance outcome work businesses are just more productive with competence but also more and more staffs openhearted accept changes and relate to greater work item satisfaction and pledge towards the job amongst its workforce. They did not ascertain any signal of high-performance outcome workplace practice system tempt any negative side-effect on workforce job related stress level. Workforce who have options to participate are not probable to label that they regu- larly have annoyances on their work or that more work is bestowed to them to what can be delivered.

Thompson (2000) preached that habitually urbane deduction for aerospace with 20 per cent of United Kingdom airline enterprises using the High-Performance Outcome Work-Practices to a prominent standard. Thompson additionally highlighted many point-to-point for the HPWPs to progress as a part of any organization and even true for every Bank. The writer appealed that despite vigorous signals of hopeful impacts, corporations are not fundamentally persuaded by the enactment of high outcome procedures is expected to give results for their companies or banks or find the accepting HPWPs too arduous. This is also understood with discrete business vertical example different banks have different acceptance.

Cappelli and Neumark (2001) set foundation that workrotation and procedural training bestowed to workers are surely associated to their current level of performance in examples of both Italian as well as British corporations. With their examination, they recognized that British corporations are fairly more productive then their Italian counterpart. The unlike methods by adjudging them to shop-floor methods, skillset and workforce relations amounted to 40 per cent of the variance. In both explanations, the initiation of team cooperation principles proposes a moderately noteworthy chapter along the restructuring procedure of companies and service sector. Thus, discrepancy in the technique of espousal of the high-performance outcome work systems observes impact their effectiveness for a establishment even in-service sector.

Lepak and Snell (2002) found that certain high-performance innate matter such as training the workforce and their skillset advancement and enhancing the delivered service quality are an domineering portion in the forthcoming events as it was in the history for all corporations as well as Banks. Technology in history and in future as well will transform the way HRM outcome practices are steered these days. HR workforce need to understand new and forthcoming generations view of work and so; they need to develop and rely on new tools and mechanisms for HRM outcome practice implementation to be imagined via HPWPs. In today's situation where outsourcing is an industry norm and way of resource engagement, deliberated human resource planning and high-outcome work practices are in the sun rise time in front of them to add banking value to future Banks performance. Supplementary, for healthcare segment the resolute of HRM of the hospitality trading will have to reflect several propensities and will be susceptible by local regulations.

Ethira et al (2005) measured research on the Dublin hotels that showed some of the people centric work methodologies associated to superior work standard recital implementation and practices. They detected partial concentrations of worker influence, intellectuals deal with the same and are the actually the foundations of high-outcome based HR work-practices. 
Obeidat, et.al., (2016) has directed a research paper to highlight the affiliation amid (HPWP) high-performance work practices and Banks and Organization performance with a more than one dimensional mechanism of the affiliation amid HPWP and their performances, this hypothesizes HPWP conferring to the capability, inspiration and opportunity framework.

Odiaka, K., \& Chang, K. (2019) deliberates the implication of HPWPs High-Performance Work Practices and examines its bearing to workforce rendezvous and performance in the country Nigeria. Conclusions illustrates that when workforces sense more allegiance to their work item or services, they are highly susceptible to buttress the HPWPs, knowing its reputation and signifying inspired performance. The affiliation amid HPWPs and performance consequences is reinforced by decision-making trust in workforce's competence and gratefulness for the work completed.

\section{ReSEARCH Methodology}

Sample Size: The entire sample comprises of 800 workforces employed at managerial levels from banking sector. Out of the total sample 400 each workforce fit into public and private sector bank correspondingly. Questionnaire was circulated over HR of the bank branches with previous consent from the Banking companies elucidating the resolve of the study. The questionnaires entail of demographic factors as: Name; Marital Status; Age; Educational Qualification; Gender; Rank; Duration of work experience; and the Wage (as voluntary).

\section{A. Research questions:}

Check if the variables of High-Performance outcome Work Systems impact the Private and Government owned banks contrarily?

\section{B. Objectives of the Study:}

The aim of the paper is to understand the variable factors impact on High-Performance Work Outcome Practices pertinent to public and private sector banks.

\section{Hypotheses:}

The hypothesis identified for this paper as trails:

$\mathrm{H} 1$ : There exist a significant variance amid factors of HPWPs in public and private sector banks.

H1a: There exist a significant variance amid factors of Training in public and private sector banks.

H1b: There exist a significant variance amid factors of Job Participation in public and private sector banks.

H1c: There exist a significant variance amid factors of Job Specification in public and private sector banks.

H1d: There exist a significant variance amid factors of Job Security in public and private sector banks.

\section{Methodology}

\section{A. Instruments and Scoring}

Instruments: Subsequent questionnaire was entrusted for conducting this paper:

High-Performances Outcome Work Practices is gauged on a eighteen items scale, basically rationaled on four facets explicitly: Training, Work Specification, Work Participation and Work Seurity this was initially industrialized by Delery and Doty (1996) with twenty three items which later-on revised by Longzeng Wu, et.al. (2011). Contributors were requested to answer on a 7-point Likert-scale oscillating from $1=$ strongly disagree to $7=$ strongly agree. The general reliability co-efficient of this scale was instituted to be comparatively high at 0.84 .

Scoring and Analysis: The manual directives defined the scoring. The further scrutiny was conducted by T-Test by computing the Mean and SDs. For the detailed analysis of collected data SPSS V. 20.0 was deployed.

\section{RESULTS AND INTERPRETATIONS}

The t-test was considered to identify the variances amid the four variables and total HPWP of Public and Privat banking workforce. The results display that there is a significant variance exist amid the two banking groups amongst the different dimensions of HPWP. The resultant p-value (.05) demonstrates that variance exist between the sample population.

Table 1 specifies the significant variance exist in the demonstration of HPWPs $(\mathrm{t}=3.88, \mathrm{p}<0.05)$. The mean score as well at 183.70 , which is on higher level in evaluation to that of Public sector banking workforces $(\mathrm{M}=$ 162.44), thus this explains that the private bank workforces display higher levels of HPWP in operations.

Additional to this, Table-1 designates the significant variances in the proportions of HPWP. The temperament of training is sophisticatedly higher $(\mathrm{t}$-value $=2.436, \mathrm{p}<0.05)$, as the mean score of Public sector banking workforces is higher $(M=29.52)$ in comparison to the mean score of private sector banking workforces, at 26.61. Thus, a significant variance in the Job Participation of Public and private bank workforces at $\mathrm{t}$-value computed as $3.60, \mathrm{p}<0.05$. This is seeming that the demonstration of Job Participation is higher for private sector banking workforces as $\mathrm{M}=35.93$ and that of Public sector banking workforces at $\mathrm{M}=29.89$. A significant variance is found in the Job specification of Public and private banking workforces (t-value $=3.95, \mathrm{p}<$ $0.05)$, this highlights that this variable factor is voiced more in private banking workforce with $\mathrm{M}=29.52$ with assessment of Public sector banking workforce of mean score as 26.61. There is significant variance in the Job Security of Public and private banking workforce with the computed tvalue as 2.88, $\mathrm{p}<0.05$. It is clear from the result that Job Security is more in case of Public sector banking workforces as $M=15.67$ and in private sector banking workforces as $M=13.57$. As in full, the result table specifies that 
TABLE 1

T-TEST STATISTICS: HPWP

\begin{tabular}{|c|c|c|c|c|c|c|c|}
\hline Variables & & $\mathrm{t}$-Value & Df & Mean & Std. Deviation & Std. Error Mean & $\mathrm{P}$ value \\
\hline \multirow{2}{*}{ Training } & \multirow{2}{*}{$\begin{array}{l}\text { Publics } \\
\text { Privates }\end{array}$} & \multirow[t]{2}{*}{2.436} & \multirow[t]{2}{*}{798} & 29.52 & 4.793 & .508 & 0.03 \\
\hline & & & & 26.61 & 4.748 & .425 & \\
\hline \multirow{2}{*}{$\begin{array}{l}\text { Job } \\
\text { Participation }\end{array}$} & Publics & 3.60 & 798 & 29.89 & 8.711 & .779 & 0.02 \\
\hline & Privates & & & 35.93 & 4.562 & .484 & \\
\hline \multirow{2}{*}{$\begin{array}{l}\text { Job } \\
\text { Specification }\end{array}$} & Publics & 3.95 & 798 & 26.61 & 5.586 & .500 & 0.01 \\
\hline & Privates & & & 29.52 & 4.902 & .520 & \\
\hline \multirow[b]{2}{*}{ Job Security } & Publics & 2.88 & 798 & 15.67 & 4.798 & .525 & 0.03 \\
\hline & Privates & & & 13.57 & 4.723 & .408 & \\
\hline \multirow[b]{2}{*}{ HPWPs } & Publics & 3.88 & 798 & 162.44 & 23.245 & 2.079 & 0.02 \\
\hline & Privates & & & 183.70 & 19.171 & 2.032 & \\
\hline
\end{tabular}

Note: Public and Private Banking Sector

the HPWPs of private sector banking workforces is higher compared to Public sector banking workforces.

\section{DISCUSSION}

An assessment amid Public and Private banking companies was one main purpose of this research paper. It was pertinent, consequently, to witness previously relating the two different types of banking sector, to check if the government sector and privately held banks are affected by the perceptions vis-à-vis HPWP variables. The reaction of the workforce queries to a greater degree, be suggestive of the work environment, policies and or operational procedures that occur among the Banks. These are in addition to these procedures and policies which shape the HPWPs.

Hypothesis- 1 of this paper projected to calculate the variances concerning the four variable dimensions to total HPWPs deployed in Public and private banking workforces.

The outcome from isolated t-test proves the above stated variance in mean is noteworthy in case of HPWPs, workforce of privately held banks has described greater overall HPWP practices (table 1) that to Public sector banks. Seemingly the likely motive in NCR region based private-sector bank has adopted more pragmatic approach in deploying HPWPs when compared to their Public-sector banking counterparts. One of the HPWP variable "training" is reported to be on higher side in government owned banks when compared to privately held banks. This hints due to the fact that in government owned establishments training is compulsory part for the Banks before an staff starts to spend efforts on. The next HPWP variable "Job participation" is testified highly in privately held banks when compared to Public sector banking establishment, the outcome may be ascertained to private banks provide autonomy to staff to deliver the services which are connected to more involvement at the work item. The Third HPWPs variable dimension "Job Specification" is reported at higher levels in private banks when matched against the Public sector banking, this could be ascertained to Public sector bank at recruitment, the KSA of workforce was checked and then the workforce's recruitment process starts. On the other hand, in private banks, specification of job takes emphasis while practically orientation of workforce started. The last variable dimension of HPWP "job security" is reported on higher level in Public sector banking when tested against the private banks. In NCR region workforces are more protected work in government owned banks with no distress of losing someone's work. However, in privately held banking sector, insecurity prevails remains.

\section{CONCLUSION}

The present study has examined the significant differences among the different dimensions of HPWP. For gauging HPWP, Longzeng Wu, et.al. (2011) scale was utilized. Whereas a evaluation amid the public and private sector banking is the fundamental core of the paper. Perception is also examined of public and private sector banking for HPWPs. The sample size consisted of 800 Workforces.

Following conclusions resulted out here are:

- HRM practices based on HPWPs of privately held banking sector are reasonably healthier to the government held banking.

- Government held banks are doing good for the variable dimension 'training' due to higher budget authorized by government of India for training tenacities.

- Private sector banking is doing well when compared to Public banks for the variable 'job participation' ascertained to work culture of private sector banking in 
India. The level of contribution in job by workforce is more in private sector banking ascertained to fear of laying off by the private banks on non-performance.

- Private sector banks are doing better when faired to Public sector banking in job specification because of amiable HR practices offered by private banks.

- Public sector banking is delivering better in comparison to private banks on the job security front because of an environment of security for the long-term job within public sector banks in India.

\section{LIMITATIONS AND RECOMMENDATIONS}

There are certain limitations which need to be addressed. The sample was choosen from a specific NCR, India region. It could be highly proper and motivating to choose a varied sample from different part country and socio-economical class clearly depict the results among the Banks. It is suggested to research a sector wise differences of HPWP in these results can be protracted to other specialists and nonprofessionals working in other businesses. Future research should be performed on the same sector after this new mergers and joint ventures which is going to be implemented by April 2020 which gives interesting findings to the researchers. It is also suggested to do the longitudinal research which could let scholars to advance their insights into the sector-wise variances of HPWP. Expectedly, this paper on baking sector will serve as a insight for such research.

\section{REFERENCES:}

[1] Appelbaum, E. \& Batt, R. (1995). 'Worker Participation in Diverse Settings: Does the Form Affect the Outcome, and, If So, Who Benefits?'. British Journal of Industrial Relations, 33(3), 353-378.
[2] Cappelli, P. \& Neumark, D. (2001). 'Do High-Performance Work Practices Improve Establishment-Level Outcomes?'. Industrial and Labor Relations Review, 54, 4, 737-75

[3] Delery, J. and Doty, D.H. (1996), "Modes of theorizing in strategic human resource administration: test of universalistic, contingency, and configurational performance predictions", Academy of Administration Journal, Vol. 39, No. 4, pp. 802835.

[4] Ethiraj, S. K., Kale, P., Krishnan, M. S., \& Singh, J. V. (2005). Where do capabilities come from and how do they matter? A study in the software services industry. Strategic administration journal, 26(1), 25-45.

[5] Lepak, D. P., \& Snell, S. A. (2002). Examining the human resource architecture: The relationships among human capital, employment, and human resource configurations. Journal of administration, 28(4), 517-543.

[6] Obeidat, S., Mitchell, R. and Bray, M. (2016), "The link between High-Performance work practices and Banksal performance: Empirically validating the conceptualization of HPWP according to the AMO model", Workforce Relations, Vol. 38 No. 4, pp. 578-595. https://doi.org/10.1108/ER-082015-0163

[7] Odiaka, K., \& Chang, K. (2019). HPWP (High-Performance Work Practices) and Its Role on Promoting the Workforce Performance in the Nigerian Hotel Industry. Journal of Banksal https://doi.org/10.33423/jop.v19i6.2661

[8] Thompson, P., (2001) "Systems of Production, Markets, Banks and Performance", Workforce Relation, 25(3), 627629.

[9] Wu, L., Wei, L. Q., Zhang, Y., \& Han, T. (2011). Workforce experienced HPWPs and job performance: Roles of personjob fit and intrinsic motivation. Frontiers of Business Research in China, 5(3), 344-363.

[10] Agarwal, S. (2020). Gender Differences in Quality of Work Life: An Empirical Study. International Journal of Knowledge-Based Organizations (IJKBO), 10(4), 52-59 (ISSN: 2155-6393). 